\title{
Changes in the rumen metabolism of sheep given increasing amounts of linseed oil in their diet
}

\author{
BY J. W. CZERKAWSKI, W. W. CHRISTIE, \\ GRACE BRECKENRIDGE AND MARGARET L. HUNTER \\ The Hannah Research Institute, Ayr $\mathrm{KA}{ }_{5} \mathrm{HL}$
}

(Received I3 June I974-Accepted 9 October 1974)

\begin{abstract}
1. Linseed oil was incorporated gradually into the diet of four sheep until the animals received $90 \mathrm{~g}$ additional fat $/ \mathrm{d}$. Attempts were made to measure changes in concentration of substances and rates of synthesis in the rumen directly, and by incubation of rumen contents in vitro (zero-time technique).

2. The high-fat diet increased the dilution rate and the volume of rumen contents and decreased the synthesis of diaminopimelic acid in the rumen. The number of protozoa decreased and the number of bacteria increased in the rumen of animals receiving the high-fat diet.

3. The concentration of volatile fatty acids (VFA) in the rumen decreased for sheep given the high-fat diet, but the capacity of rumen contents to produce VFA in vitro increased.

4. The incorporation of radioactivity from $\left[{ }^{14} \mathrm{C}\right]$ acetate into lipids during incubation of rumen contents in vitro increased with the amount of linseed oil in the diet. The greatest proportional increase was with the bacterial fraction of rumen contents.

5. In the group of four animals used, one animal showed consistent differences in the magnitude of the measured variables. This animal appeared to have a smaller rumen, a lower dilution rate and larger concentrations of some substances in the rumen. A higher proportion of fatty acids appeared to be synthesized by the micro-organisms from this animal.
\end{abstract}

Several workers have demonstrated lipid synthesis in the rumen (Sutton, Storry \& Nicholson, 1970; Ørskov, Fraser \& McDonald, I971 ; Bickerstaffe, Noakes \& Annison, I 972) and Bickerstaffe et al. (1972) found that the net lipid synthesis was greater with high-fat diets. In our earlier work (Czerkawski, I 966) when the intake of linseed-oil fatty acids was increased gradually to a level that constituted $18 \%$ of the total energy content of the diet, there was inhibition of methane production, a small increase in faecal excretion of cellulose and crude lipid, but no change in faecal excretion of nitrogen. Further experiments in which linseed-oil fatty acids or linseed oil were added to the diet of sheep in increasing amounts (Czerkawski, 1973), showed that the changes in the fermentation patterns were similar for all sheep, but in some, lipid metabolism in the rumen appeared abnormal in as much as there was considerable accumulation of palmitic acid and smaller amounts of myristic acid. It was concluded on the basis of these experiments that the increases in concentration of palmitic acid were due to the increased synthesis of this compound in the rumen, and an indirect estimate of the magnitude of this synthesis was made. The value was similar to those obtained by direct measurements reported by other workers. However, there were a number of puzzling features. For instance, the changes in fermentation pattern, such as inhibition of methane production, decreased concentration of acetate and butyrate in the rumen, or increased excretion of lipid in the faeces, occurred in all sheep irrespective of whether there was a large synthesis of palmitic acid or not. It was suggested 
that the increase in lipid synthesis occurred in all sheep, but in those sheep that had unchanged concentrations of palmitic acid, other fatty acids and possibly more complex lipids were being synthesized.

It appeared possible that the lowering of the concentration of acetate in the rumen in this instance was not the result of decreased production, but rather increased utilization, such as one would expect if lipid synthesis increased. Inhibition of methane production results in an excess of reduced cofactors, which would also favour increased lipid synthesis from acetate. As the biggest proportion of the energy cost of lipid synthesis in terms of ATP is required for the regeneration of reduced cofactors, and since these are probably present in excess under the conditions of the experiments, lipid synthesis is relatively inexpensive.

The object of the present experiment was to get support or otherwise for the above ideas, by attempting to measure changes in microbial growth, volatile fatty acid (VFA) production and lipid metabolism by more direct techniques.

\section{EXPERIMENTAL}

Animals and feeding regimens. The animals (four wethers, with rumen fistulas) were kept in animal cages throughout the experiment. The food consisted of $800 \mathrm{~g}$ basaldiet cubes and $100 \mathrm{~g}$ hay daily. Half the daily ration was given at 09.00 hours and the other half together with hay was given at 17.00 hours. The additional lipid (linseed oil) was incorporated into the cubes in three increments to give nominally $3^{\circ}, 60$ and $9 \circ \mathrm{g}$ linseed oil/d to each sheep, the basal diet remaining the same. The basal-diet cubes had the following composition $(\mathrm{g} / \mathrm{kg})$ : barley meal 252 , ground barley straw $\mathrm{I} 26$, oat meal I26, molassed sugar-beet pulp $3^{6}$ and dried-grass meal 454 . To this were added the following minerals $(\mathrm{g} / \mathrm{kg}): \mathrm{NaCl}$ ı。, $\mathrm{CaHPO}_{4} 5$ and $\mathrm{MgO}$ I. The linseed oil was added in the required amounts before cubing.

The sheep were kept for 4 weeks on the basal diet $\left(\mathrm{AI}_{-}-\mathrm{A}_{4}\right.$, where $\mathrm{A}$ is the experimental period during which this diet was fed and $A I$ is the first week of this period). They were then given the diet containing $3 \circ \mathrm{g}$ linseed oil/d for 3 weeks $\left(\mathrm{BI}_{\mathrm{I}}-\mathrm{B}_{3}\right)$, then the diet containing $60 \mathrm{~g}$ linseed oil/d for 3 weeks $\left(\mathrm{CI}_{\mathrm{I}}-\mathrm{C}_{3}\right)$. The diet containing the largest amount of oil $(9 \circ \mathrm{g} / \mathrm{d})$ was given for 9 weeks $\left(\mathrm{D} \mathrm{I}_{\mathrm{I}}-\mathrm{D} 9\right)$. Finally, the sheep were again given basal diet for 3 weeks $\left(\mathrm{A}_{5}-\mathrm{A}_{7}\right)$. There were no refusals, but some sheep took longer to eat their ration for $\mathbf{I - 2} \mathrm{d}$ after the lipid content had been increased (no measurements were made during these periods). The sampling was usually confined to the last week of periods A, B and C, and weeks 3,6 and 9 of period D, and occasionally samples were taken at the end of the second week of each period.

In order to achieve better control over feeding and to facilitate sampling, the animals were kept in metabolism cages. Previous experience showed that it was inadvisable to keep sheep under these conditions longer than $5^{-6}$ months. It was important to make the period on the high-fat diet as long as possible and therefore the transition periods $\mathrm{B}$ and $\mathrm{C}$ were limited to 3 weeks each. It is possible that the time required to reach a steady-state on the lower-fat diets would be less than the time on the highest-fat diet, so the measurements made during the transition periods could be 
valid. However, the main interest was in measuring the effect of high-fat treatment, and the measurements for periods $\mathrm{B}$ and $\mathrm{C}$ should be considered as incidental.

Sampling of rumen contents. Two sampling procedures were used. If rumen contents were required for incubations in vitro, samples of about $100 \mathrm{ml}$ were removed from the rumen of each sheep by means of a suction device (Alexander \& McGowan, I966) before the morning feed and strained through four layers of gauze before use. On other occasions, when the object was to measure the changes in concentration of substances in the rumen with respect to feeding, small samples of about 10-20 $\mathrm{ml}$ were taken by means of a probe described by Czerkawski (1973). These samples were also strained before analysis.

Fractionation of rumen contents and incubations in vitro. The strained, pre-feed samples of rumen contents $(50 \mathrm{ml})$ were fractionated as follows. Samples were centrifuged at $520 \mathrm{~g}$ for $30 \mathrm{~min}$ at room temperature, the residues were resuspended in $40 \mathrm{ml} \mathrm{NaCl}$ solution $(9 \mathrm{~g} / \mathrm{l})$ and again centrifuged at $520 \mathrm{~g}$ for $30 \mathrm{~min}$ to give a residue consisting of food particles, protozoa and some large bacteria $(\mathrm{PB})$ and a supernatant liquid which was centrifuged at $27000 \mathrm{~g}$ for $30 \mathrm{~min}$ at the same time, but separate from the supernatant fraction from the first centrifugation. The two residues contained mainly small bacteria and were pooled to give the bacterial fraction (SB). The supernatant fraction containing saline was discarded but the fraction containing clarified rumen fluid (CRF) was retained. Although the fractions were not pure, the procedure was designed to produce fractions of rumen contents greatly enriched with particular micro-organisms and which could be obtained rapidly in view of the subsequent incubations to be done.

For incubation, $\mathrm{PB}$ (the coarse particle fraction) was suspended in $15 \mathrm{ml} \mathrm{CRF}$, and $\mathrm{SB}$ was suspended in ro $\mathrm{ml} \mathrm{CRF}$. Subsequently, the following were set up in ro $\mathrm{ml}$ glass-stoppered centrifuge tubes: $4 \mathrm{ml}$ suspension $\mathrm{PR}+4 \mathrm{ml} \mathrm{CRF} ; 4 \mathrm{ml}$ suspension $\mathrm{SB}+4 \mathrm{ml} \mathrm{CRF} ; 4 \mathrm{ml}$ suspension $\mathrm{PB}+4 \mathrm{ml}$ suspension $\mathrm{SB} ; 8 \mathrm{ml}$ original rumen contents $(\mathrm{R})$.

A solution $(2 \mathrm{ml})$ of sodium $\left[\mathrm{I}^{14} \mathrm{C}\right]$ acetate $(\mathrm{I} \mu \mathrm{mol} ; 2.5 \mu \mathrm{Ci})$ was added to each tube. Thus, the total volume of liquid in each tube was $10 \mathrm{ml}$ and the gas space was minimal. The contents of the tubes were mixed gently by inverting for a few minutes and $\mathrm{I} .0 \mathrm{ml}$ samples were withdrawn for analysis. Glucose solution $(5 \circ \mathrm{mg}$ in $0.5 \mathrm{ml})$ was added to each tube and the tubes were incubated at $39^{\circ}$ for $2.0 \mathrm{~h}$, then a further $5^{\circ} \mathrm{mg}$ glucose in $0.5 \mathrm{ml}$ water was added to each tube and the tubes were incubated for a further $2 \cdot 0 \mathrm{~h}$. The tubes were stoppered loosely during incubation to allow the gases to escape. At the end of incubation, $1.0 \mathrm{ml}$ of the contents of each tube was withdrawn and kept for analysis and the remaining $9.0 \mathrm{ml}$ were used for lipid extraction and analysis. All incubations were done in the same way, but not all samples were analysed. The dilution of samples caused by addition of glucose was corrected for in subsequent calculations.

Analysis of steam-VFA. The initial and final $\mathrm{r} \cdot 0 \mathrm{ml}$ samples were pipetted into centrifuge tubes containing $0 . \mathrm{I} \mathrm{ml} 5 \mathrm{M}-\mathrm{H}_{2} \mathrm{SO}_{4}$, allowed to stand for $15 \mathrm{~min}$ and centrifuged. The supernatant fractions $(0.5 \mathrm{ml})$ were pipetted into the centre wells of Conway units (Conway, 1962), which contained $4.0 \mathrm{ml}$ water in the outer space. The 
units were allowed to stay open for $\mathrm{I}_{5} \mathrm{~min}$, anhydrous $\mathrm{Na}_{2} \mathrm{SO}_{4}(3 \mathrm{~g})$ was added to the centre well and the units were covered tightly with lids that had a film of paraffin oil, before being allowed to stand overnight at room temperature. The contents of the outer wells were transferred quantitatively to small flasks and titrated with ro mM$\mathrm{NaOH}$ using a phenolphthalein indicator. The solutions of $\mathrm{Na}$ salts were made up to Io $\mathrm{ml}$ with water and $\mathrm{I} \cdot \mathrm{ml}$ samples were used for scintillation counting. Some samples were also analysed by gas-liquid chromatography (GLC) as described previously (Czerkawski, r973).

Lipid extraction and analysis. The bulk of the sample from each tube $(9 \mathrm{ml})$ was poured into $5 \mathrm{ml}$ methanol in $50 \mathrm{ml}$ round-bottomed flasks. The tubes were washed out with $4 \mathrm{ml}$ methanol, giving a total of $9 \mathrm{ml}$ methanol, and an equal volume, $9 \mathrm{ml}$, of chloroform was added. The flasks were shaken well, allowed to stand for $30 \mathrm{~min}$ and I $8 \mathrm{ml}$ chloroform-methanol $(5: \mathrm{r}, \mathrm{v} / \mathrm{v})$ was added. The flasks were shaken, and allowed to stand for $30 \mathrm{~min}$. The samples were centrifuged briefly to give an aqueous layer, a 'plug' and the lower chloroform layer. The aqueous layer was discarded and the chloroform layer was filtered through paper and taken to dryness under reduced pressure. The 'plug' was refluxed for $30 \mathrm{~min}$ with $24 \mathrm{ml}$ chloroform-methanol (2: I, $\mathrm{v} / \mathrm{v}$ ). The refluxed material was filtered through paper into the flask containing the evaporated chloroform layer. The dissolved lipid was shaken well with $6 \mathrm{ml}$ ro $\mathrm{mM}-$ $\mathrm{Na}$ acetate and centrifuged. The chloroform layer was transferred to a weighed flask and the solvent evaporated so that the crude lipid could be weighed.

The crude lipids were dissolved in $20 \mathrm{ml}$ hexane and two $\mathrm{I} \mathrm{ml}$ samples were used for measuring the amount of radioactivity. The volume of the remainder was reduced and the lipids were separated into classes as follows.

Lipid classes were separated by thin-layer chromatography (TLC) using silica gel G (0.5 mm thick; E. Merck AG, Darmstadt, W. Germany); hexane-diethyl etherformic acid $(80: 20: 2$, by vol.) was the developing solvent. Lipids were visualized under ultraviolet light after spraying with $2^{\prime}, 7^{\prime}$-dichlorofluorescein in methanol ( $\mathrm{m} \mathrm{m} / \mathrm{l}$ ) and were identified by co-chromatography with authentic standards. The appropriate bands of silica gel were transferred into scintillation vials and were suspended in Unisolve I (Koch-Light Laboratories, Colnbrook, Bucks.) for the measurement of radioactivity by liquid-scintillation counting.

The fatty acids in the lipids obtained from incubations of SB and R were converted to methyl esters, separated from the other lipids and the amount of radioactivity in the total fatty acids was determined as follows. Methyl [IO, $\mathrm{II}^{-3} \mathrm{H}$ ] heptadecanoate (Christie \& Hunter, 1973) of similar total activity and specific activity to the sample to be analysed, was added as an internal standard to the lipids or lipid extracts which were trans-esterified in methanolic hydrogen chloride solution $(5 \circ \mathrm{g} / \mathrm{l})$. The methyl esters were isolated and purified by TLC using silica gel $\mathrm{G}$ with hexane-diethyl ether $(90: 10, \mathrm{v} / \mathrm{v})$ as the developing solvent. Methyl esters were recovered from the adsorbent by elution with diethyl ether for the measurement of radioactivity by dualisotope liquid-scintillation counting. The proportion of the ${ }^{14} \mathrm{C}$ in the fatty acid portion of the lipid was determined by relating the ${ }^{14} \mathrm{C}:{ }^{3} \mathrm{H}$ ratio in the purified methyl esters to that of the original sample with the added internal standard. 
Towards the end of the experiment, when the sheep had been given the high-fat diet for a long time, the methyl esters of fatty acids were separated by preparative GLC and the amount of radioactivity in the individual fatty acids was determined as follows. Fatty acid methyl esters were isolated using a Pye I04 gas chromatograph (Pye-Unicam Ltd, Cambridge). Components were separated according to chainlength using $2.134 \mathrm{~m} \times 9.5 \mathrm{~mm}$ glass columns packed with SE-30 on Chromosorb $\mathrm{G}$ $(50 \mathrm{~g} / \mathrm{kg}$; Phase Separations Ltd, Queensferry, Flints.) and were vented by means of a stream splitter through a heated outlet for collection in traps containing glass beads moistened with toluene (Christie, 1974). Esters were recovered from the traps by elution with toluene-fluor ( $4 \mathrm{~g}$ PPO and $0.2 \mathrm{~g}$ POPOP/l toluene) for the measurement of radioactivity.

For routine determination of the total fatty acid content for pre-feed samples and samples of rumen contents taken at various times with respect to feeding, the lipids were extracted using the method of Folch, Lees \& Sloane Stanley (1957) and the fatty acids were esterified and analysed as described previously (Czerkawski, 1966).

Estimation of microbial population. A proportion of samples of rumen contents taken for incubation experiments was kept for the estimation of the size of the microbial population which was made microscopically (see Meynell \& Meynell, 1965) using Helber counting chambers with Thoma ruling for bacteria, and Manners counting chambers for protozoa. The Helber and Manners counting chambers were supplied by Gelman-Hawksley, Lancing, Sussex.

Marker experiments. The marker experiments were done towards the end of periods $\mathrm{A}_{3}, \mathrm{C}_{2}, \mathrm{D}_{5}$ and $\mathrm{A} 6$ of the experiment. The marker, $20 \mathrm{~g}$ polyethylene glycol (PEG), was introduced into the rumen of each sheep in $200 \mathrm{ml}$ water. Attempts were made to distribute the marker throughout the rumen by injecting it in four portions into different sites. Exactly i $h$ before the morning feed a sample of rumen contents was taken and the marker was injected. The animals were given their rations and samples were withdrawn at $0.5, \mathrm{I}, 2,3,4,6$ and $8 \mathrm{~h}$ after feeding. The samples were strained through four layers of gauze and $4 \mathrm{ml}$ were set aside for the determination of PEG. The remainder was weighed and dried to constant weight at $100^{\circ}$. The dried samples were ground and used for the determination of $\mathrm{N}$ and diaminopimelic acid (DAP) contents.

DAP content was determined in $100 \mathrm{mg}$ samples by the method of Czerkawski (1974) and the amount of PEG was determined by the method of Hydén (1961) adapted for the Pye AC 60 discrete sample autoanalyser (it was necessary to cut a new template for the purpose). The reagents were added and the extinction recorded at precise time intervals; it was possible to analyse forty samples $/ \mathrm{h}$ in triplicate. $\mathrm{N}$ content was determined for $50 \mathrm{mg}$ samples of dry rumen contents. These were digested with I $\mathrm{ml}$ water, $\mathrm{I} \cdot 5 \mathrm{~g}$ catalyst (potassium sulphate-selenium, 100: $\mathrm{I}, \mathrm{w} / \mathrm{w}$ ), $3 \mathrm{ml}$ concentrated, $\mathrm{N}$-free $\mathrm{H}_{2} \mathrm{SO}_{4}$-orthophosphoric acid $(95: 5, \mathrm{w} / \mathrm{w})$ and $\mathrm{r}_{4} \cdot \mathrm{ml} \mathrm{H}_{2} \mathrm{O}_{2}$ solution $(300 \mathrm{ml} / \mathrm{l})$ for $\mathrm{I} h$ and made up to $50 \mathrm{ml}$ with water. The concentrations of $\mathrm{NH}_{3}$ were determined using a Pye AC 6o discrete sample autoanalyser (Pye-Unicam Ltd, I968). The mean recovery of $\mathrm{N}$ in $\mathrm{NH}_{4} \mathrm{Cl}$ taken through the procedure was IOI $\pm 3 \%$ for four determinations made at different times. 


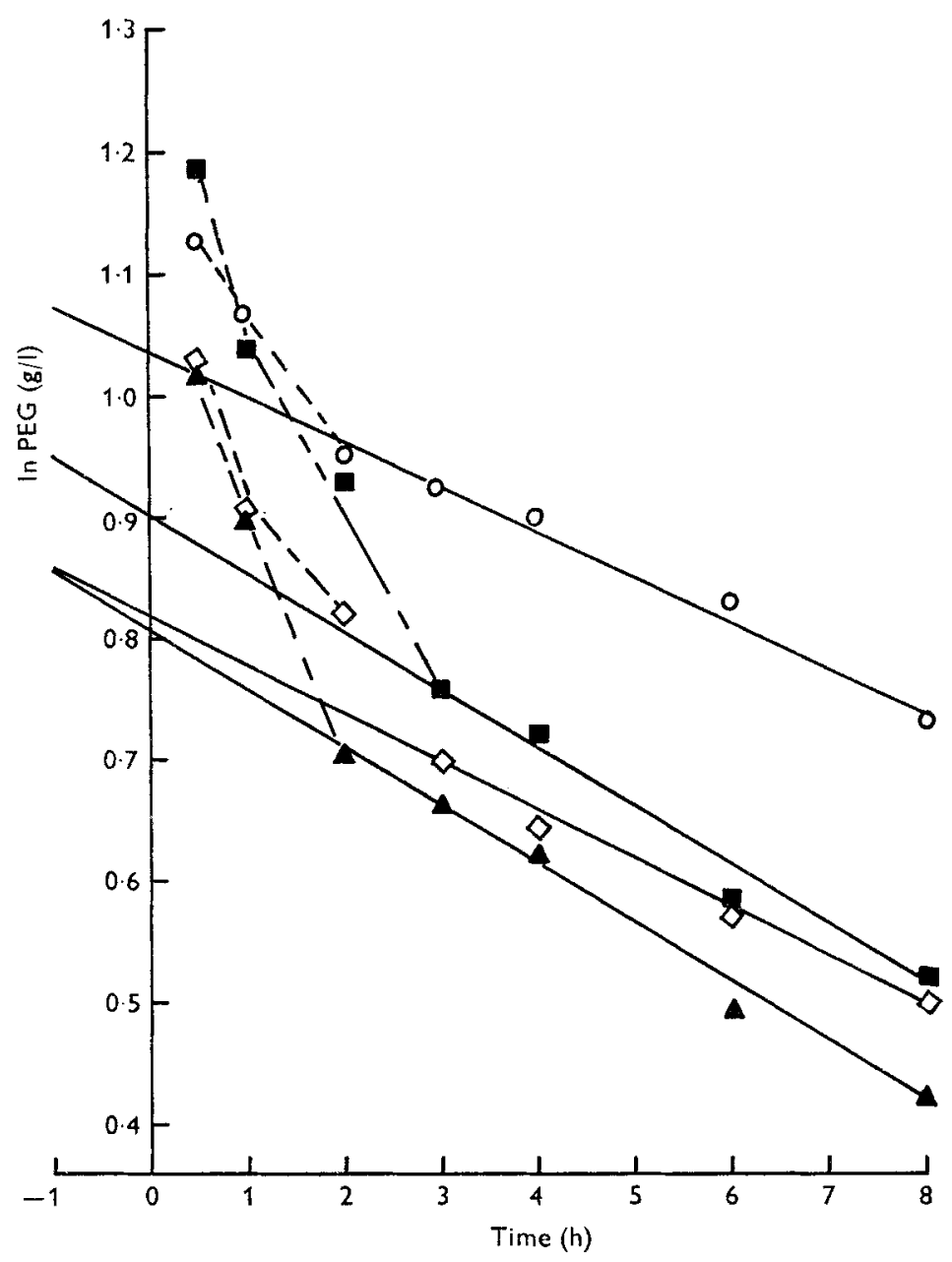

Fig. I. Log (In) concentrations of polyethylene glycol (PEG) in rumen samples $v$. time after feeding for sheep given increasing amounts of linseed oil in their diet. Each point is the mean value for four sheep. $O, A_{3} ; \Delta, C_{2} ; \boldsymbol{M}, D_{5} ; \square, A 6 . A, C, D$, the experimental periods when the sheep had been given for the number of weeks indicated the basal diet alone (weeks $1-4$ and $20-22$ of the experiment), or with 60 (weeks 8-10 of the experiment) or 90 (weeks I I-I9 of the experiment) g linseed oil/d respectively. For details of diets, see p. 26 .

Measurement of radioactivity. Radioactivity in samples was measured using a liquid-scintillation spectrometer (Tricarb Model 2425; Packard Instruments, Caversham, Reading, Berks.). Counting efficiencies for each channel were determined using an automatic external standard calibrated for the purpose and values obtained in counts/min were then converted to disintegrations/min. In some experiments the amount of radioactivity was measured using the Unilux II scintillation counter (Nuclear Chicago, High Wycombe, Bucks.). The counting efficiency was determined using the 'channels ratio' technique. The toluene-fluor scintillant described pre- 
Table I. Changes in mean dilution rates and volumes of rumen contents for sheep given increasing amounts of linseed oil in their diet

(Mean values with their standard errors for four sheep)

\begin{tabular}{|c|c|c|c|c|}
\hline \multirow{2}{*}{$\begin{array}{l}\text { Experimental } \\
\text { period }\end{array}$} & \multicolumn{2}{|c|}{$\begin{array}{l}\text { Dilution } \\
\text { rate }(/ d)\end{array}$} & \multicolumn{2}{|c|}{ Volume (1) } \\
\hline & Mean & SE & Mean & SE \\
\hline $\mathrm{A}_{3}$ & 0.99 & 0.12 & $6 \cdot 6$ & 0.4 \\
\hline $\mathrm{C}_{2}$ & $I \cdot I 6$ & 0.15 & $7 \cdot 5$ & I. 6 \\
\hline $\mathrm{D}_{5}$ & $I \cdot 17$ & 0.24 & $8 \cdot 3$ & 0.2 \\
\hline A6 & 0.96 & 0.34 & $8 \cdot 2$ & 0.9 \\
\hline
\end{tabular}

A,C,D, the experimental periods when the sheep had been given for the number of weeks indicated the basal diet alone (weeks $I-4$ and 20-22 of the experiment), or with 60 (weeks 8-10 of the experiment) or 90 (weeks $1 \mathrm{I}-\mathrm{I} 9$ of the experiment) g linseed oil/d respectively. For details of diets, see p. 26.

viously was used for lipids and the commercial preparation Unisolve I was used for aqueous solutions or silica-gel suspensions.

\section{RESULTS}

\section{Dilution of PEG and changes in concentration of $N$ and DAP in the PEG space}

Passage of PEG in the rumen. The natural logs of the mean concentrations of PEG in the rumen of the four sheep at various times after feeding are shown in Fig. r. The values deviated from a simple exponential for up to about $3 \mathrm{~h}$ after feeding. It can be shown that the system can be described more accurately in terms of a two-compartment model in which it is assumed that the food just consumed is for a time accessible to water but not to PEG, thus creating a second compartment within the rumen. It is possible to estimate the variables of the second exponential term and obtain various constants that define the model, but with limited accuracy.

It was sufficient, however, for the purposes of this report to confine attention to the time $3-8 \mathrm{~h}$ after feeding and to assume a single exponential function describing the rumen as a single-compartment system. The slopes of the linear portions of the curves in Fig. I gave the dilution rates which are summarized in Table I. The volumes of PEG space in the rumen (volume of water in the rumen that is accessible to PEG), also given in Table $\mathrm{I}$, were calculated by extrapolating to time, $t=-\mathrm{I}$ ( $\mathrm{I} \mathrm{h}$ before feeding) and correcting for the volume of water in the dose of PEG (Hydén, 196I). Increasing the fat content of the diet resulted in a small increase in dilution rates and appeared to increase the volume of rumen contents.

Changes in concentration of $N$ and $D A P$. There was considerable variability in the concentration of $\mathrm{N}$ and DAP when the results were expressed per unit volume of rumen contents, but a definite pattern could be discerned, showing a decrease in concentration of both substances soon after feeding, an increase $\mathrm{I}-3 \mathrm{~h}$ after feeding and a steady concentration during the period $3-8 \mathrm{~h}$ after feeding. However, when the results were expressed as weight per unit weight of $\mathrm{PEG}$, the variability was reduced. The log plots of concentrations of $\mathrm{N}$ and DAP expressed on a PEG basis gave straight 


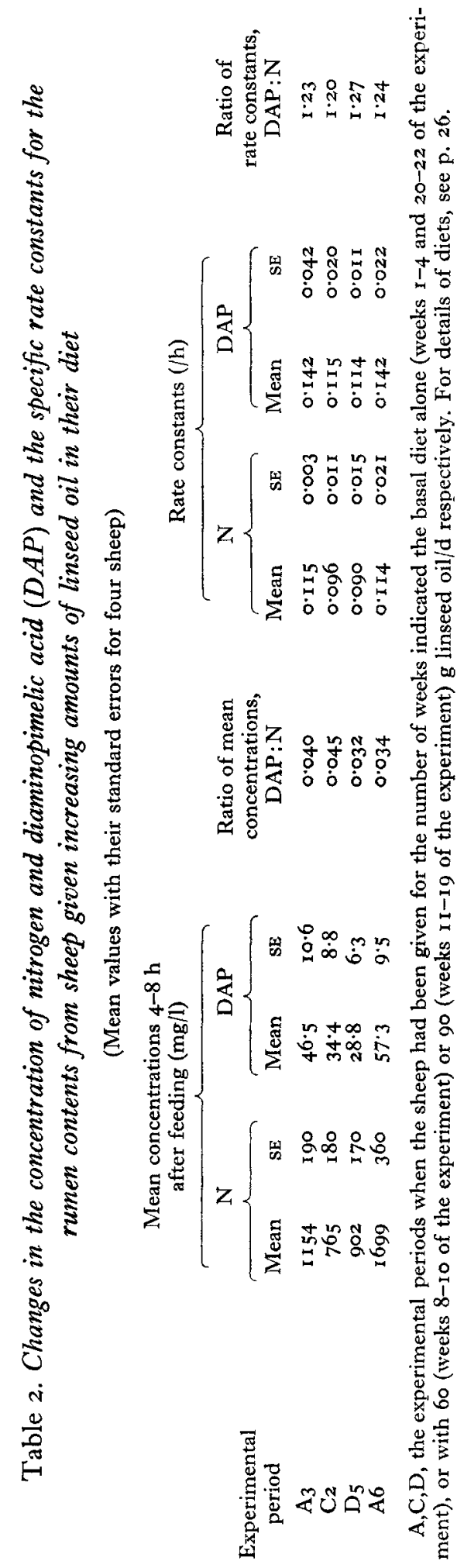


Table 3. Estimation of the formation of microbial matter in terms of nitrogen and diaminopimelic acid $(D A P)(m g / h)$ in the polyethylene glycol space in the rumen of sheep 4-8 $h$ after feeding

(Mean values for four sheep)

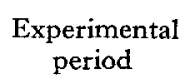

A3

$\mathrm{C} 2$

15

A6

\begin{tabular}{|c|c|}
\hline \multicolumn{2}{|c|}{ Rate of formation } \\
\hline $\mathrm{N}$ & DAP \\
\hline 875 & 43.5 \\
\hline $55^{\circ}$ & $29 \cdot 7$ \\
\hline 675 & $27 \cdot 2$ \\
\hline 1587 & $66 \cdot 7$ \\
\hline
\end{tabular}

A,C,D, the experimental periods when the sheep had been given for the number of weeks indicated the basal diet alone (weeks $1-4$ and 20-22 of the experiment) or with 60 (weeks 8-10 of the experiment) or 90 (weeks I I-I9 of the experiment) $g$ linseed oil/d respectively. For details of diets, see p. 26.

lines with positive slopes between 3 and $8 \mathrm{~h}$ after feeding (correlation coefficient $0.94-0.99$ ). On integrating equation 3 (Czerkawski, 1973) between the limits $t=0$ and $c=C_{0}$, the following was obtained:

$$
C=C_{0} \exp (-(D-k) t),
$$

where $C$ is the concentration of the substance in the rumen at time $t, D$ is the dilution rate and $k$ is the specific net rate of formation. If the substance is neither produced nor degraded, for example PEG, $k=0$ and we get:

$$
C^{\prime}=C_{0}^{\prime} \exp (-D t)
$$

Dividing equation $\mathrm{I}$ by equation 2, we obtain:

$$
\frac{C}{C^{\prime}}=\frac{C_{0}}{C_{0}^{\prime}} \exp (k t) .
$$

When $\log _{\mathrm{n}}(\ln )$ of equations 2 and $3\left(\ln C^{\prime}\right.$ and $\ln \left(C \div C^{\prime}\right)$ respectively) are plotted $v$. time, the slopes give the dilution rate and the rate constant direct.

The mean concentrations of $\mathrm{N}$ and DAP between times 3 and $8 \mathrm{~h}$ after feeding and the specific rate constants are given in Table 2 . There was a decrease with the high-fat diet followed by an increase during $\mathrm{A}_{5}-\mathrm{A}_{7}$ that made the final control value higher than the original control value. There were similar changes in the specific rate constants.

Estimate of rate of synthesis of microbial matter. The actual rate of formation of a substance can be obtained from the specific rate $(k)$, the concentration $(C)$ and the volume $(V)$, by using the simple relationship: rate of formation $=k \times C \times V$. This was done to obtain the values given in Table 3 . Two assumptions must be made in order to relate these values to net synthesis of microbial matter; ( $\mathrm{I}$ ) the $\mathrm{N}$ in strained rumen contents is mostly microbial $\mathrm{N}$ and (2) the DAP content of the microbial matter does not change in the course of the experiment. Neither assumption is correct.

The results in Table 2 indicate that whereas the ratio of concentrations, DAP:total $\mathrm{N}$ changed during the experiment, the ratio of their rate constants did not. This 
Table 4. Size of the microbial population in the rumen of sheep given increasing amounts of linseed oil in their diet

(Mean values with their standard errors for four sheep)

\begin{tabular}{|c|c|c|c|c|c|c|c|}
\hline \multirow{2}{*}{$\begin{array}{l}\text { Experimental } \\
\text { period }\end{array}$} & \multicolumn{2}{|c|}{$\begin{array}{c}\text { Total bacteria } \\
(\text { no. } / \mathrm{ml})\left(\times 10^{-10}\right)\end{array}$} & \multicolumn{2}{|c|}{$\begin{array}{l}\text { Large bacteria } \\
(\text { no. } / \mathrm{ml})\left(\times 10^{-9}\right)\end{array}$} & \multicolumn{2}{|c|}{$\begin{array}{c}\text { Protozoa } \\
\text { (no. } / \mathrm{ml})\left(\times 10^{-5}\right)\end{array}$} & \multirow[b]{2}{*}{ Notes } \\
\hline & Mean & SE & Mean & SE & Mean & SE & \\
\hline$A_{3}$ & 3.5 & 0.8 & 0.5 & 0.4 & $15 \cdot 8$ & 3.01 & $3-4 \%$ \\
\hline $\mathrm{B} 2$ & 4.0 & I. 6 & $2 \cdot 3$ & $\mathrm{I} \cdot 7$ & $6 \cdot 6$ & $2 \cdot 2\}$ & Holotrichs \\
\hline $\mathrm{C}_{2}$ & $4 \cdot I$ & 0.5 & $2 \cdot 9$ & $I \cdot 3$ & $1 \cdot 0$ & 0.4 & - \\
\hline $\mathrm{D}_{2}$ & $9 \cdot 2$ & $3 \cdot 6$ & $1 \cdot 5$ & $I \cdot 5$ & 0.7 & $1 \cdot 7$ & 一 \\
\hline $\mathrm{D}_{4}$ & $6 \cdot 8$ & 3.9 & 0.6 & 0.5 & $1 \cdot 2$ & 0.8 & - \\
\hline D6 & $9 \cdot 4$ & $I \cdot 2$ & $I \cdot I$ & 0.6 & 0.3 & 0.1 & - \\
\hline D8 & $17 \cdot \mathbf{I}$ & $6 \cdot 0$ & 0.4 & 0.2 & 0.4 & $0 \cdot \mathrm{I}$ & - \\
\hline A6 & 13.2 & $1 \cdot 2$ & 0.1 & 0.1 & $21 \cdot 2$ & 10.2 & $\begin{array}{l}\text { All protozoa } \\
\text { small }\end{array}$ \\
\hline
\end{tabular}

$A, B, C, D$, the experimental periods when the sheep had been given for the number of weeks indicated the basal diet alone (weeks $I-4$ and $20-22$ of the experiment), or with 30 (weeks $5-7$ of the experiment), 60 (weeks $8-10$ of the experiment) or 90 (weeks II-I9 of the experiment) g linseed oil/d respectively. For details of diets, see p. 26.

indicated that the change in $\mathrm{N}$ content was microbial in origin, but the concentration of $\mathrm{N}$ is not wholly microbial. It was shown previously that the large bacteria have smaller proportions of DAP than the small bacteria (Czerkawski, 1974) and it is possible that the decrease in concentration and synthesis of DAP with the high-fat diet could be the result of an increase in the number of large bacteria. The values given in Table 3 refer to $4-8 \mathrm{~h}$ after feeding; up to $4 \mathrm{~h}$ after feeding, concentrations were lower and consequently the rates of synthesis were lower.

The values given in Tables $I-3$ are mean values with their standard errors for four sheep. There was large variation between animals, but the results were consistent within individual animals. For example, the mean concentrations for DAP $4-8 \mathrm{~h}$ after feeding were calculated from three separate estimations for each sheep. For period $\mathrm{A}_{3}$ they were $24 \cdot 9 \pm \mathrm{r} \cdot 9,75^{\cdot} \cdot 9 \pm 3 \cdot 9,4^{2} \cdot 7 \pm 7 \cdot 5$ and $42 \cdot 6 \pm 2 \cdot 3 \mathrm{mg} / \mathrm{l}$ for sheep nos. $554,55^{6}$, 564 and 565 respectively. Similarly, when the log concentrations of PEG or the log concentrations N:PEG or DAP:PEG were plotted $v$. time, the correlation coefficients were in most instances greater than 0.9 , but the actual slopes varied between sheep. As a rule the values for one sheep were markedly different from the values for the other three sheep. In general the concentrations of $\mathrm{N}$ and DAP in the rumen 4-8 h after feeding were markedly higher for sheep no. $55^{6}$ than for the other three sheep. The variation of the slopes for the log plots was less predictable, but was less than the variation in concentration.

\section{Microbial population and the production of VFA}

Size of microbial population. It is difficult to obtain reliable information from estimates of the microbial population. The results given in Table 4 suggested that the total number of bacteria increased considerably throughout the experiment and there 
Table 5. Pre-feeding concentration and in vitro production of total volatile fatty acids in the rumen contents from sheep given increasing amounts of linseed oil in their diet, during incubation of unfractionated rumen contents with $\left[{ }^{14} \mathrm{C}\right]$ acetate

(Mean values with their standard errors for four sheep)

\begin{tabular}{|c|c|c|c|c|c|}
\hline \multirow[b]{2}{*}{ Experimental period } & \multicolumn{2}{|c|}{$\begin{array}{c}\text { Concentration } \\
(\mu \mathrm{mol} / \mathrm{ml})\end{array}$} & \multicolumn{2}{|c|}{$\begin{array}{l}\text { Production rate } \\
(\mu \mathrm{mol} / \mathrm{ml} \text { per } \mathrm{h})\end{array}$} & \multirow[b]{2}{*}{$\begin{array}{l}\text { Total production } \\
\text { (mol/sheep per d) }\end{array}$} \\
\hline & Mean & $\overline{\mathrm{SE}}$ & Mean & $\mathrm{SE}$ & \\
\hline $\mathrm{A}_{4}$ & $44 \cdot 5$ & $5 \cdot 5$ & 5.8 & $I \cdot I$ & 0.92 \\
\hline $\mathrm{B}_{3}$ & $34{ }^{\circ}$ & $3 \cdot 2$ & $9 \cdot I$ & 0.4 & $1 \cdot 53^{*}$ \\
\hline $\mathrm{C}_{3}$ & $18 \cdot 9$ & $2 \cdot 4$ & $8 \cdot 7$ & 0.8 & $\mathrm{I} \cdot 57$ \\
\hline $\mathrm{D}_{3}$ & $26 \cdot 0$ & $4 \cdot 5$ & 6.9 & 0.9 & $I \cdot 3 I^{*}$ \\
\hline D6 & $28 \cdot 4$ & $2 \cdot 8$ & $12 \cdot 7$ & $I \cdot 4$ & $2 \cdot 53$ \\
\hline D9 & $29 \cdot 5$ & $4 \cdot 8$ & 14.0 & 0.9 & $2 \cdot 70^{*}$ \\
\hline
\end{tabular}

$A, B, C, D$, the experimental periods when the sheep had been given for the number of weeks indicated the basal diet alone (weeks $1-4$ and $20-22$ of the experiment), or with 30 (weeks $5-7$ of the experiment), 60 (weeks 8-10 of the experiment) or 90 (weeks $\mathrm{I} \mathrm{I}-\mathrm{I} 9$ of the experiment) $\mathrm{g}$ linseed oil/d. For details of diets, see p. 26.

* Rumen volumes estimated by interpolation.

was also some increase in the number of large bacteria when the animals received 30-60 g linseed oil/d. The number of protozoa decreased considerably when sheep were given additional fat in their diet. When the sheep were given the basal diet again (A6) the number of protozoa increased considerably, but they were small.

On the whole the estimates of the microbial population were not consistent with the DAP concentrations given in Table 2. If we assume that the concentration of bacteria during periods $D_{4}-\mathrm{D} 6$ was twice as large as during periods $\mathrm{A2}-\mathrm{B2}$, and if we assume that the microbial-matter concentration during period $\mathrm{A}_{3}$ was the same as during period $\mathrm{D}_{5}$, then the results would indicate that the proportion of DAP in bacterial matter with the high-fat diet was only about one-third of that with the basal $\operatorname{diet}\left(\mathrm{A}_{\mathbf{I}}-\mathrm{A}_{4}\right)$.

$V F A$. The mean concentrations of total VFA in pre-feed samples of rumen contents from the four sheep are given in Table 5, together with the rates of production calculated from the decrease in the amount of specific radioactivity for total VFA during incubation of unfractionated rumen contents with $\left[{ }^{14} \mathrm{C}\right]$ acetate. The mean production of total VFA in sheep was calculated by multiplying the values for production rate (Table 5) by the volume of rumen contents (actual and interpolated values from Table I). The values were somewhat lower than those reported by Blaxter (1967), but nevertheless suggested that the linseed oil added to the diet did not depress VFA production but might actually increase it. However, this could not be taken as support for increased microbial growth as it was possible that under these conditions growth and fermentation became uncoupled.

\section{Lipid metabolism}

Changes in lipid concentrations. The concentrations of crude lipid in the rumen increased considerably when sheep were given increasing amounts of linseed oil in 


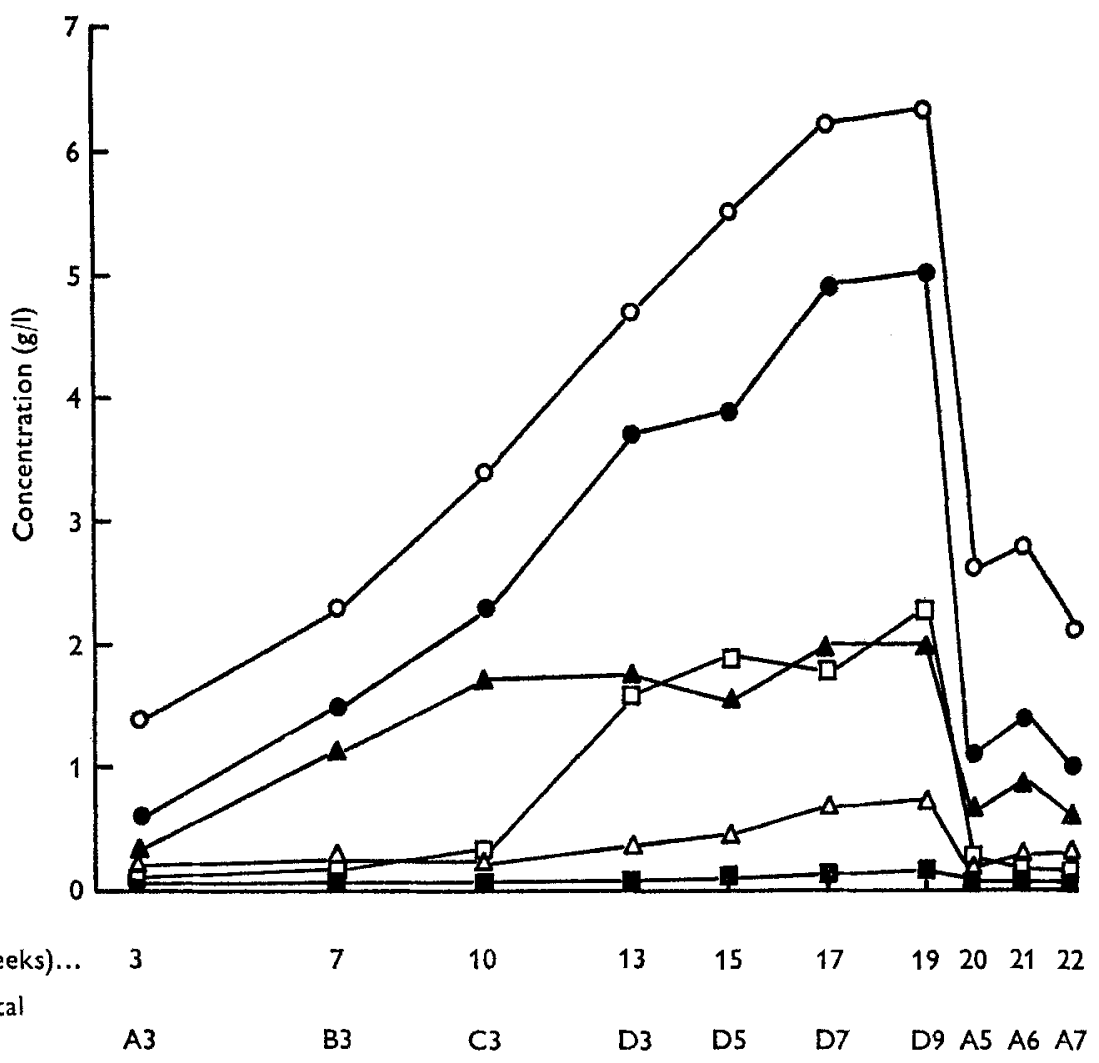

Fig. 2. Changes in the concentration of total lipid and individual fatty acids in pre-feed samples of rumen contents from sheep given increasing amounts of linseed oil in their diet. $O$, Total lipid;, total fatty acids; $\triangle$, palmitic acid; $\Delta$, stearic acid; $\square$, monoenoic $C_{18}$ fatty acids; E, polyunsaturated $C_{18}$ fatty acids. $A, B, C, D$, the experimental periods when the sheep had been given for the number of weeks indicated the basal diet alone (weeks $1-4$ and $20-22$ of the experiment), or with 30 (weeks $5-7$ of the experiment), 60 (weeks 8 -10 of the experiment) or 90 (weeks I I-I 9 of the experiment) $g$ linseed oil/d respectively. For details of diets, see p. 26.

their diets (Fig. 2). The proportion of the total fatty acids in the lipid extract was about $50 \%$ with the basal and the low-fat diets and increased to over $75 \%$ with the high-fat diet. The concentrations of stearic acid increased steadily when the linseed oil content of the diet was increased to $60 \mathrm{~g} / \mathrm{d}$ and did not change with increased content of fat or prolonged feeding of the high-fat diet. When there was no further increase in the concentration of stearic acid, the concentration of monoenoic acids, which had remained low, increased rapidly to values that were similar to those of stearic acid. Thus it appeared that the hydrogenation of polyunsaturated fatty acids became less efficient when the dietary linseed oil was increased from 60 to $90 \mathrm{~g} / \mathrm{d}$. The concentrations of palmitic acid increased with the high-fat diet $\left(D_{7}, D_{9}\right)$ while the polyunsaturated acid concentration remained low throughout, never exceeding $0.1 \mathrm{~g} / 1$.

The results for the concentrations of long-chain fatty acids in the rumen of sheep during periods $\mathrm{A}, \mathrm{C}$ and $\mathrm{D}$ for up to $8 \mathrm{~h}$ after the morning ration are not given here. 
Table 6. Incorporation of radioactivity from $\left[{ }^{14} \mathrm{C}\right]$ acetate into lipids during incubation of rumen fractions* $(P B$ and $S B)$ and whole rumen contents $(R)$ from sheep given increasing amounts of linseed oil in their diet

(Mean values with their standard errors for four sheep)

\begin{tabular}{|c|c|c|c|c|c|c|c|c|}
\hline \multirow{3}{*}{$\begin{array}{c}\text { Experimental } \\
\text { period }\end{array}$} & \multicolumn{8}{|c|}{ Incorporation of ${ }^{14} \mathrm{C}$ (disintegrations $/ \mathrm{min}$ per $10 \mathrm{ml}$ per $\left.\mathrm{h}\right)\left(\times 10^{-3}\right)$} \\
\hline & \multicolumn{2}{|c|}{$\mathrm{PB}$} & \multicolumn{2}{|c|}{ SB } & \multicolumn{2}{|c|}{$\mathrm{PB}+\mathrm{SB}$} & \multicolumn{2}{|c|}{$\mathbf{R}$} \\
\hline & Mean & SE & Mean & SE & Mean & SE & Mean & SE \\
\hline $\mathrm{A}_{4}$ & 4.3 & 0.4 & $I \cdot I$ & 0.1 & $4 \cdot 6$ & 0.6 & $5 \cdot 3$ & 0.6 \\
\hline $\mathbf{B}_{3}$ & 9.0 & 0.5 & $2 \cdot 3$ & 0.3 & 10.9 & $x \cdot 6$ & $14 \cdot 4$ & $2 \cdot 6$ \\
\hline $\mathrm{C}_{3}$ & $17 \cdot 2$ & $I \cdot 3$ & $8 \cdot 5$ & $2 \cdot 9$ & $21 \cdot 3$ & $2 \cdot 7$ & $20 \cdot I$ & $2 \cdot 3$ \\
\hline $\mathrm{D}_{3}$ & $8 \cdot 3$ & $x \cdot 6$ & 13.5 & $4 \%$ & 15.7 & $2 \cdot 3$ & 14.6 & 0.5 \\
\hline D6 & 12.9 & $\mathrm{I} \cdot 5$ & 17.0 & $x \cdot 6$ & $17 \cdot 2$ & $I \cdot 2$ & $15 \% 7$ & $I \cdot I$ \\
\hline Do & II I I & $3 \%$ & 19.7 & $7 \cdot 1$ & 18.5 & 3.4 & $20 \cdot 6$ & 2.9 \\
\hline
\end{tabular}

PB, protozoa + food particles + some bacteria; SB, bacteria, very few protozoa; $A, B, C, D$, the experimental periods when the sheep had been given for the number of weeks indicated the basal diet alone (weeks $1-4$ and $20-22$ of the experiment), or with 30 (weeks $5-7$ of the experiment), 60 (weeks 8-10 of the experiment) or 90 (weeks I $1-19$ of the experiment) $g$ linseed oil/d respectively. For details of diets, see p. 26 .

*For details of procedures, see p. 27.

There were increases in polyunsaturated fatty acids $0 \cdot 5-2 \cdot 0 \mathrm{~h}$ after feeding during period $C$ and much larger, although temporary, increases with the high-fat diet (period D). There were corresponding decreases in the concentrations of stearic and monoenoic acids between 0.5 and $2.0 \mathrm{~h}$ after feeding. The concentrations of all acids returned to pre-feed values about $3 \mathrm{~h}$ after feeding and it must be concluded that the detailed pre-feed results given in Fig. 2 were probably representative of the rumen during the greater part of the day.

Incorporation of $\left[{ }^{14} C\right]$ acetate into total lipids. The incorporation of radioactivity into crude lipids during incubation of the different fractions of rumen contents increased with increasing linseed oil content of the diet (Table 6). The increases were somewhat irregular with PB (protozoal fraction). This was not surprising, since microscopic examination indicated that there had been a considerable reduction in the number of protozoa in sheep given the high-fat diet ('Table 4). However, the extent of incorporation increased steadily when $\left[{ }^{14} \mathrm{C}\right]$ acetate was incubated with $\mathrm{SB}$ (bacterial fraction). The incorporation of radioactivity increased with increasing fat content of the diet when the regenerated rumen contents $(P B+S B$ ) and $R$ (unfractionated rumen contents) were incubated with $\left[{ }^{14} \mathrm{C}\right]$ acetate. Clearly, the extent of incorporation was not additive in as much as the sum of $\mathrm{PB}$ and $\mathrm{SB}$ was greater than incorporation in the regenerated fraction. Moreover, the incorporation of radioactivity by $\mathrm{R}$ was on the whole somewhat greater than in the regenerated fraction $(P B+S B)$, although the concentration of micro-organisms in the latter was about three times greater than in the rumen.

Fractionation of the rumen contents apparently caused some loss of capacity to 


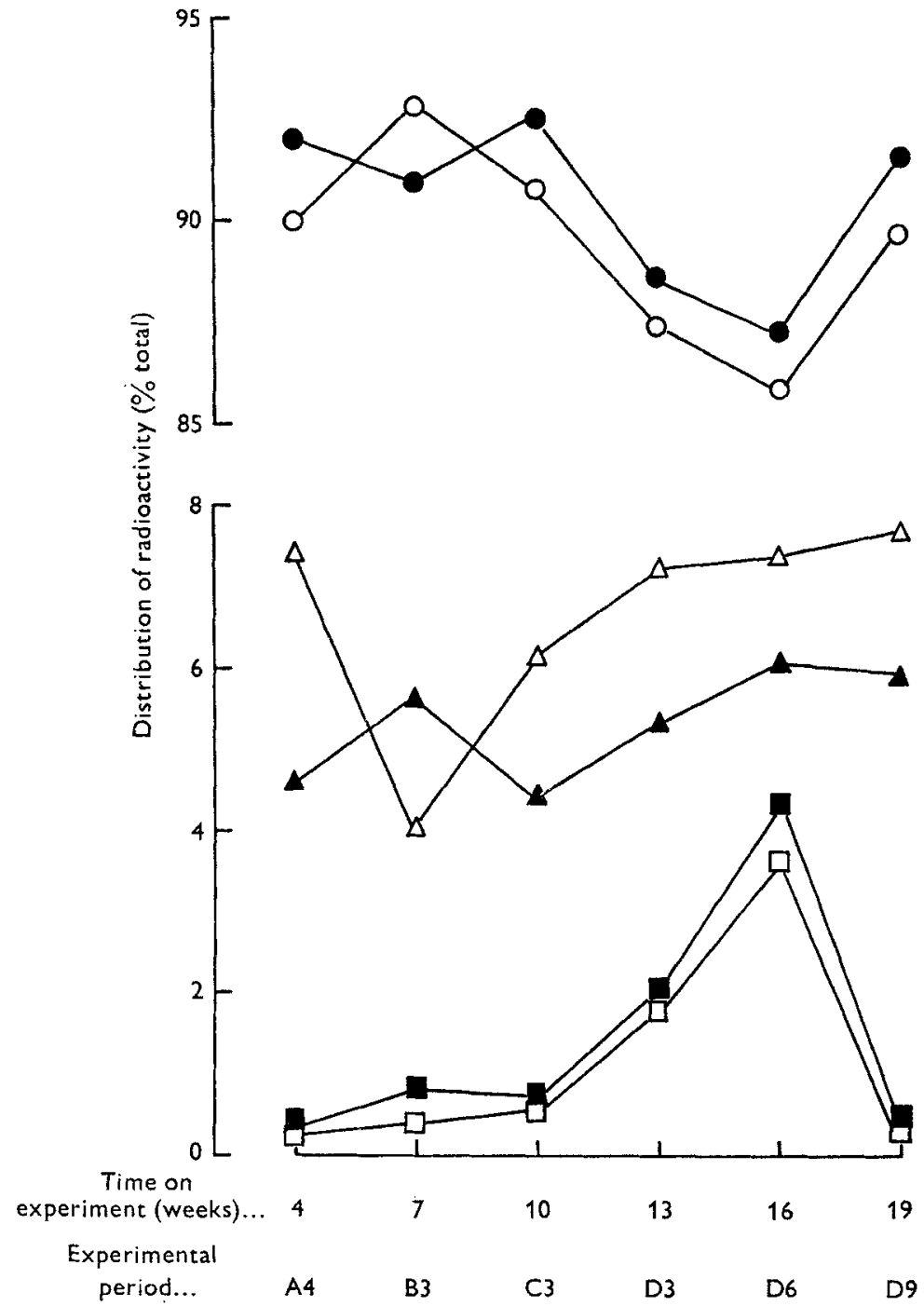

Fig. 3. Distribution of radioactivity in classes of lipids after in vitro incubation with $\left[{ }^{14} \mathrm{C}\right]$ acetate of unfractionated rumen contents $(O, \triangle, \square)$ and the bacterial fraction from rumen contents

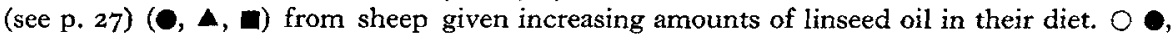
Complex lipids; $\triangle, \Delta$, free fatty acids; $\square$, triglycerides. $A, B, C, D$, the experimental periods when the sheep had been given for the number of weeks indicated the basal diet alone (weeks $\mathrm{x}-4$ and 20-22 of the experiment), or with 30 (weeks 5-7 of the experiment), 60 (weeks 8-10 of the experiment) or 90 (weeks II-I9 of the experiment) $\mathrm{g}$ linseed oil/d respectively. For details of diets, see p. 26.

synthesize lipids. It is possible that the synthesis of lipid from acetate would be even greater in the rumen. The large and regular increases in incorporation by SB throughout the experiment suggested that much of the increased synthetic activity was confined to bacteria. The maximal incorporation of radioactivity was 20600 disintegrations $/ \mathrm{min}$ per sample per $\mathrm{h}$, that is, $8.9 \%$ of the added radioactivity would be incorporated in $24 \mathrm{~h}$. Since the daily production of VFA was $2.7 \mathrm{~mol} / \mathrm{d}$ with the high-fat 


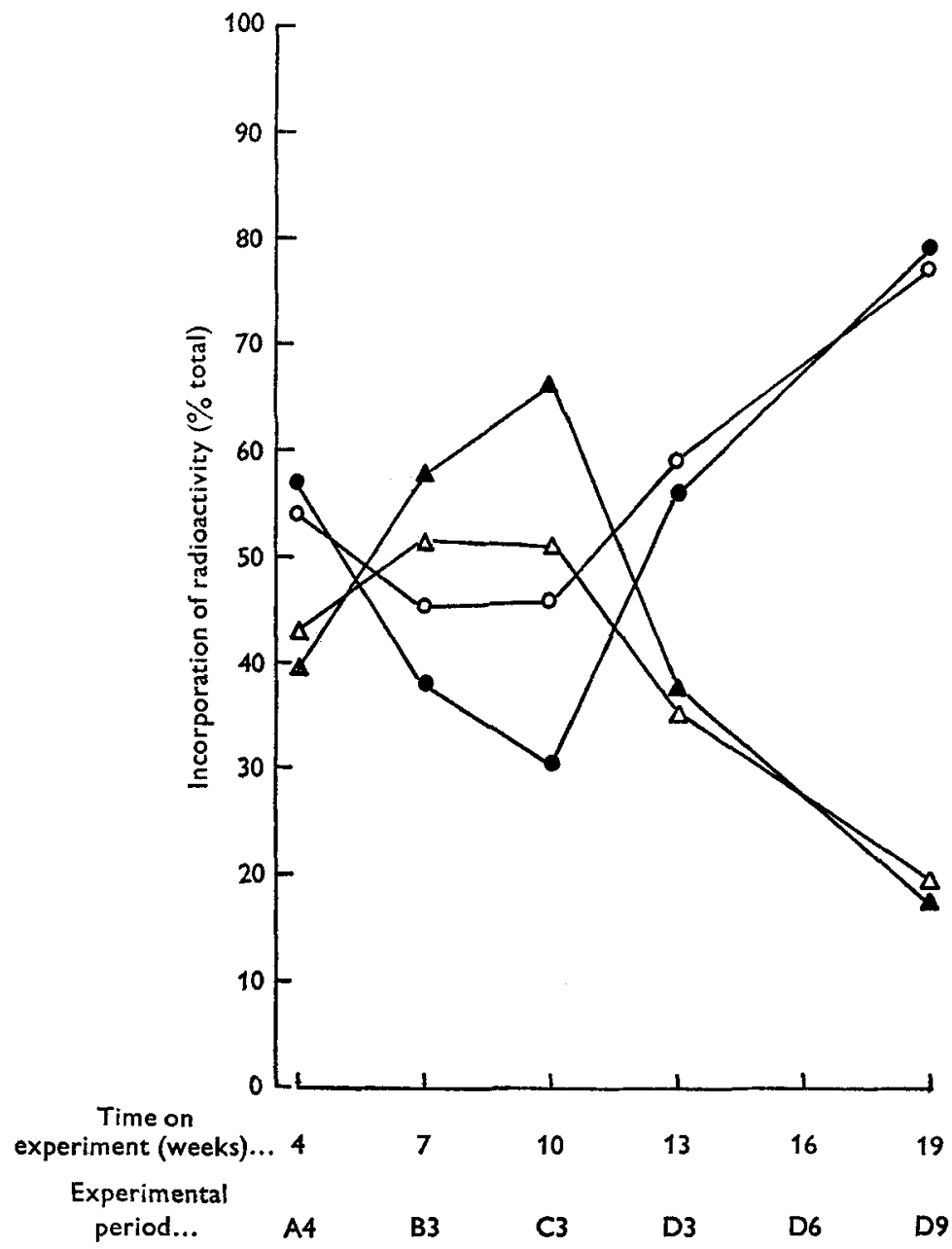

Fig. 4. Incorporation of radioactivity from [ $\left[{ }^{14} \mathrm{C}\right]$ acetate into total fatty acids $(0,9)$ and pigments $(\Delta, \Delta)$ during in vitro incubation of unfractionated rumen contents $(0, \Delta)$ and the bacterial fraction from rumen contents (see p. 27) $(\boldsymbol{O}, \Delta)$ from sheep given increasing amounts of linseed oil in their diet. A,B,C,D, the experimental periods when the sheep had been given for the number of weeks indicated the basal diet alone (weeks $1-4$ and 20-22 of the experiment), or with 30 (weeks $5-7$ of the experiment), 60 (weeks 8-10 of the experiment) or 90 (weeks II-19 of the experiment) $\mathrm{g}$ linseed oil/d respectively. For details of diets, see p. 26 .

diet, it follows that the lipid synthesis with this diet could be $7 \cdot 7 \mathrm{~g} / \mathrm{d}$ in terms of palmitic acid. It is likely that the synthesis of lipid by rumen micro-organisms in vivo might be considerably greater. This result confirmed earlier 'indirect' estimates which showed that up to $25 \mathrm{~g}$ additional lipid could be synthesized/d in the rumen of sheep given linseed oil with their diet (Czerkawski, 1973).

Distribution of radioactivity in lipid classes. The separation of lipids into classes by TLC showed that between 85 and $95 \%$ of the total radioactivity was in the "complex lipid' fraction, which also contained pigments. The free fatty acids contained 4-10\% 
Table 7. Variation within animals in the concentrations $(\mathrm{g} / \mathrm{l})$ of dry matter, crude lipid and palmitate, dilution rates and rumen volumes for pre-feed samples from the rumen of individual sheep given the basal diet* alone (experimental period A†) or with $90 \mathrm{~g}$ linseed oilld (high-fat diet) (experimental period $D \dagger$ )

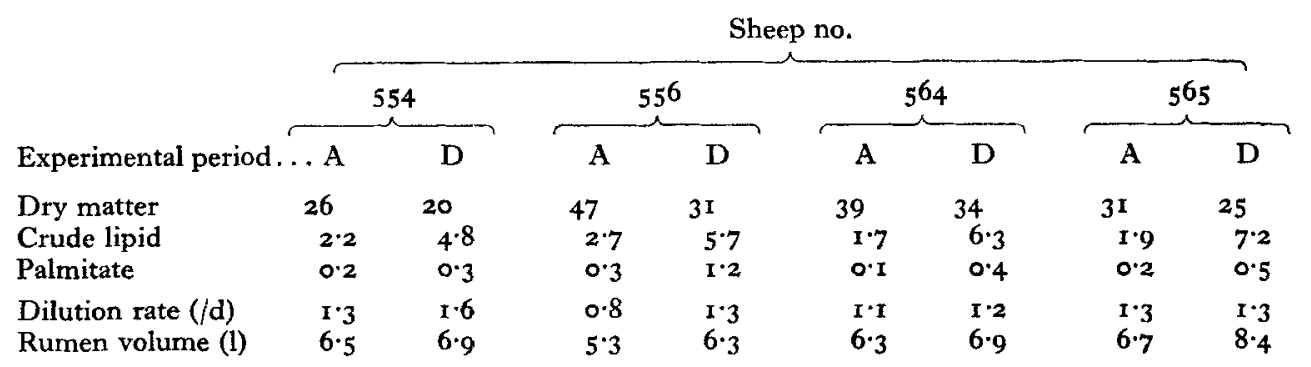

* For details of diet, see p. 26 .

+ The sheep were given the basal diet alone for weeks $\mathrm{I}-4$ and $20-22$ of the experiment and with $90 \mathrm{~g}$ linseed oil/d for weeks $\mathrm{I}$ I-I 9 of the experiment.

of the total radioactivity, and the triglycerides and diglycerides contained less than $5 \%$. The amount of radioactivity in the cholesterol esters was less than $2 \%$ of the total. In general the distribution of radioactivity in lipid classes when $\left[{ }^{14} \mathrm{C}\right]$ acetate was incubated with the different fractions of rumen contents was similar for $\mathrm{PB}$, the regenerated rumen contents $(\mathrm{PB}+\mathrm{SB})$ and $\mathrm{R}$ (unfractionated rumen contents), but was slightly different for SB (bacterial fraction). To illustrate this, the mean results for the four sheep for incubations with SB and $R$ are shown in Fig. 3. 'The incorporation of radioactivity into diglycerides and cholesterol esters was low and did not change markedly.

With the high-fat diet, SB tended to incorporate more radioactivity into diglycerides (not shown in Fig. 3), triglycerides and 'complex lipids' and less into free fatty acids than did $\mathrm{R}$. When the proportion of linseed oil in the diet was increased the relative incorporation of radioactivity into free fatty acids increased and into 'complex lipids' decreased. The incorporation of ${ }^{14} \mathrm{C}$ into triglycerides increased from very low values (up to period $\mathrm{C}_{3}$ ) to a maximum during period $\mathrm{D} 6$, whereas the incorporation into diglycerides did not change appreciably from the control value of about $2 \%$.

Incorporation of radioactivity into fatty acids. The incorporation of radioactivity into the fatty acid portion of the lipid extract was measured only in the samples obtained on incubation of SB and of $\mathrm{R}$. The results, expressed as mean values for the four sheep, are given in Fig. 4. In both fractions the incorporation of radioactivity into fatty acids decreased initially with increasing amounts of linseed oil in the diet and then increased until about $80 \%$ of the radioactivity was found in the fatty acids, the initial decrease being more marked with SB.

As the radioactivity in the triglycerides and diglycerides was small and must reside largely in the fatty acid portion, it must be assumed that the greater part of the nonfatty acid radioactivity was confined to the complex lipid fraction. A large proportion of this was probably in the form of pigments and the results in Fig. 4 indicate that the 
Table 8. Incorporation of $\left[{ }^{14} \mathrm{C}\right]$ acetate into free fatty acids $(F F A)$ and triglycerides $(T G)$ during incubation of rumen fractions* ( $P B$ and $S B)$ and whole rumen contents $(R)$ from sheep given the high-fat diet (basal diet $\uparrow+9 \circ \mathrm{g}$ linseed oilld)

(The results are expressed as a percentage of the total radioactivity and are mean values for experimental periods $D_{3}$ and D6 (weeks 13 and 16 of the experiment))

\begin{tabular}{|c|c|c|c|c|c|}
\hline \multirow[b]{2}{*}{ Sheep no. } & & \multicolumn{4}{|c|}{ Rumen fraction } \\
\hline & & PB & $\mathrm{SB}$ & $\mathbf{P B}+\mathbf{S B}$ & $\mathbf{R}$ \\
\hline 554 & $\begin{array}{l}\text { FFA } \\
\text { TG }\end{array}$ & $\begin{array}{l}6 \cdot 5 \\
5 \cdot 6\end{array}$ & $\begin{array}{l}4 \cdot 1 \\
3 \cdot 0\end{array}$ & $\begin{array}{l}5 \cdot 3 \\
4 \cdot 0\end{array}$ & $\begin{array}{l}6 \cdot 3 \\
2 \cdot 5\end{array}$ \\
\hline $55^{6}$ & $\begin{array}{l}\text { FFA } \\
\text { TG }\end{array}$ & $\begin{array}{r}10.5 \\
3.0\end{array}$ & $\begin{array}{l}6 \cdot 8 \\
2 \cdot 2\end{array}$ & $\begin{array}{r}10.6 \\
2.1\end{array}$ & $\begin{array}{r}10.1 \\
2.3\end{array}$ \\
\hline 564 & $\begin{array}{l}\text { FFA } \\
\text { TG }\end{array}$ & $\begin{array}{l}6 \cdot 1 \\
5 \cdot 0\end{array}$ & $\begin{array}{l}5 \cdot 3 \\
3 \cdot 8\end{array}$ & $\begin{array}{l}7 \cdot 4 \\
4 \cdot x\end{array}$ & $\begin{array}{l}6 \cdot 1 \\
3 \cdot 2\end{array}$ \\
\hline 565 & $\begin{array}{l}\text { FFA } \\
\text { TG }\end{array}$ & $\begin{array}{l}7.7 \\
3 \cdot 2\end{array}$ & $\begin{array}{l}6 \cdot 5 \\
3 \cdot 6\end{array}$ & $\begin{array}{l}7 \cdot 2 \\
2 \cdot 6\end{array}$ & $\begin{array}{l}7.2 \\
2.9\end{array}$ \\
\hline
\end{tabular}

PB, protozoa + food particles + some bacteria; SB, bacteria, very few protozoa.

* For details of fractionation procedure, see p. 27 .

$\uparrow$ For details of diet, see p. 26.

incorporation of radioactivity into the pigments apparently increased with increasing amounts of linseed oil in the diet and then decreased.

\section{Variation within animals}

In earlier experiments, out of nine sheep given the same diet, six sheep appeared to have a different lipid metabolism from the rest (Czerkawski, 1973). In those experiments when the sheep were given large amounts of linseed oil or linseed-oil fatty acids in their diet, the concentrations of palmitic acid increased considerably. Values for some of the variables measured are given for individual sheep in Table 7 . The only sheep that showed a marked increase in the concentration of palmitic acid similar to those obtained previously (Czerkawski, 1973) was sheep no. 556. The same sheep had a higher concentration of dry matter (DM) in the rumen and lower dilution rate consistent with an apparently smaller rumen. The concentrations of N and DAP were somewhat higher in the rumen of sheep no. $55^{6}$ than in the rumen of the other sheep when they were given the basal diet but not when they were given the high-fat diet.

The rumen contents from sheep no. $55^{6}$ also showed differences in their ability to incorporate $\left[{ }^{14} \mathrm{C}\right]$ acetate into lipids. With $\mathrm{R}$ (whole rumen contents) from this sheep (with the high-fat diet) there was greater incorporation of radioactivity into the free fatty acids and lower incorporation into triglycerides, but the differences were small with SB (bacterial fraction) (Table 8). This observation and the increase in concentration of palmitic acid in the rumen suggested that the rumen micro-organisms of sheep no. $55^{6}$ might synthesize fatty acids, in particular palmitic acid, faster than the microorganisms of the other sheep. Consequently, the methyl esters of fatty acids extracted from $\mathrm{SB}$ and $\mathrm{R}$ from samples taken during the last week of the period on the high-fat diet (D9) were isolated by preparative GLC and the radioactivity in the individual 
Table 9. Distribution of radioactivity from $\left[{ }^{14} \mathrm{C}\right]$ acetate in individual fatty acids during incubation of the bacterial fraction* of rumen contents $(S B)$ and the unfractionated rumen contents $(R)$ from sheep during the final week $\uparrow$ of the experimental period on the high-fat diet (basal diet $++90 \mathrm{~g}$ linseed oil /d)

(Results are expressed as a percentage of the total radioactivity in fatty acids)

\begin{tabular}{|c|c|c|c|c|c|c|c|c|}
\hline \multirow[b]{3}{*}{ Fatty acid } & \multicolumn{8}{|c|}{ Sheep no. } \\
\hline & \multicolumn{2}{|c|}{554} & \multicolumn{2}{|c|}{$55^{6}$} & \multicolumn{2}{|c|}{564} & \multicolumn{2}{|c|}{565} \\
\hline & SB & $\mathbf{R}$ & SB & $\mathrm{R}$ & SB & $\mathrm{R}$ & SB & $\mathrm{R}$ \\
\hline $\mathrm{C}_{12}$ & $4 \cdot 8$ & $3 \cdot 3$ & $\mathrm{I} \cdot 8$ & $5 \cdot 5$ & $2 \cdot 8$ & $x \cdot 9$ & $4 \cdot I$ & $4^{\cdot I}$ \\
\hline$C_{14}$ & I 3.0 & $18 \cdot 3$ & $20 \cdot 6$ & $9 \cdot 8$ & 12.9 & $20 \% 4$ & 14.4 & r3.3 \\
\hline$C_{1 \overline{5}}$ & I 3.6 & $2 I \cdot 4$ & $I \cdot 5$ & $23 \cdot 5$ & $2 I \cdot 4$ & $29 \cdot 4$ & $29 \cdot 8$ & $26 \cdot 4$ \\
\hline $\mathrm{C}_{18}$ & $35 \cdot 3$ & $20 \cdot 3$ & $4 I \cdot 0$ & $43^{\cdot 6}$ & $30 \cdot 0$ & $22 \cdot 3$ & $27 \cdot 2$ & $31 \cdot 9$ \\
\hline $\mathrm{C}_{17}$ & $4 \cdot 5$ & $7 \cdot 2$ & $4 \%$ & $9^{6} 6$ & $2 \cdot 7$ & 5.8 & 6.7 & $7 \cdot 6$ \\
\hline$C_{18}$ & $28 \cdot 8$ & 29.5 & $3 \mathrm{I} \cdot \mathrm{I}$ & $8 \cdot 0$ & 30.2 & $20 \cdot I$ & 17.9 & $\times 6.4$ \\
\hline & & $\begin{array}{l}* \mathrm{~F} \\
+\mathrm{W} \\
\dagger \mathrm{F}\end{array}$ & $\begin{array}{l}\text { of } \mathrm{fr} \\
\mathrm{f} \text { the } \\
\text { of } \mathrm{d}\end{array}$ & $\begin{array}{l}\text { natio } \\
\text { rime } \\
\text { see p }\end{array}$ & dure, & p. 27. & & \\
\hline
\end{tabular}

fatty acids was determined. The results are shown in Table 9. For all sheep the radioactivity was incorporated into many fatty acids during the incubation of SB and $\mathrm{R}$, but the incorporation pattern for sheep no. 556 was different from those of the other sheep. In particular, SB from sheep no. 556 had significantly more radioactivity in the $\mathrm{C}_{14}$ and $\mathrm{C}_{16}$ acids and significantly less in the $\mathrm{C}_{15}$ acids. $\mathrm{R}$ from sheep no. $55^{6}$ had significantly more radioactivity in the $\mathrm{C}_{16}$ acids and significantly less in the $\mathrm{C}_{18}$ acids.

\section{DISCUSSION}

The results reported here confirmed some of the tentative conclusions that were drawn from the earlier results (Czerkawski, I973), but also uncovered more problems. The difficulties were due to over-simplification of a complex biological system and were the consequence of attempts to extrapolate results obtained during experiments in vitro to conditions obtained in vivo, and were probably caused by the inherent variability within a 'matched' group of animals.

A very simple model was used to represent the passage of digesta in the rumen, therefore, values for dilution rates, volumes of rumen contents and estimates of rates of synthesis of microbial matter in terms of DAP, should not be considered as absolute, but rather as comparative values. With these reservations in mind, it appeared that the incorporation of large amounts of linseed oil into the diet of sheep increased the passage of digesta by increasing the dilution rate and the volume of rumen contents, and depressed the synthesis of microbial DAP.

Since there were no controls, no attempts were made to weigh the animals regularly throughout the experiment. Nevertheless, the animals were in excellent condition throughout and all gained weight. Thus, the productivity of the animals as a whole was not affected adversely even though the synthesis of microbial matter in the rumen appeared to be depressed. It is possible that when the microbial population changed 
in response to the high-fat diet the DAP content of bacteria decreased and the content of structural lipid increased. The depression in the synthesis of microbial matter in the rumen measured in terms of DAP would then be apparent rather than real. On the other hand, the depression in microbial synthesis might have been real, but could have been compensated for by increased efficiency of the lower gut.

Earlier experiments showed that the incorporation of large amounts of linseed oil in the diet of sheep caused a decrease in the concentrations of VFA in the rumen and this was largely confined to acetate and butyrate (Czerkawski, 1973). The present experiment confirmed that the concentration of VFA was depressed, but also showed that their production increased. The validity of this assertion would depend on the validity of extrapolation of incubation results to the actual rumen. 'The values calculated for the rumen, particularly with the high-fat diet, were in reasonably good agreement with the values reported in the literature on the basis of direct determinations.

The apparent depression in the synthesis of microbial matter and increased fermentation were not irreconcilable. It is possible to uncouple fermentation and growth, but such uncoupling could not be sustained in a flowing system.

The number of protozoa in the rumen of sheep during the period on the high-fat diet decreased considerably but the total number of bacteria increased. The decrease in the number of protozoa could have been due to toxicity of linseed-oil fatty acids to these organisms, but it could also have been the result of reduced sequestration of these micro-organisms in the rumen (Hungate, Reichl \& Prins, 1971). The increase in the number of bacteria in the rumen was not consistent with the DAP concentration unless the DAP content of bacteria in the rumen of animals when they were given the high-fat diet was much less than when they were given the basal diet. The resolution of the problem would require isolation of the bacteria and the determination of the DAP content.

The incorporation of radioactivity from $\left[{ }^{14} \mathrm{C}\right]$ acetate into lipids during the incubation of fractions of rumen contents increased when the sheep were given linseed oil with their diet. An extrapolation of these results to the rumen suggested a synthesis of about ro $g$ additional lipid/d. An indirect estimation (Czerkawski, 1973) suggested that about $25 \mathrm{~g}$ lipid/d might be synthesized under these conditions, and direct measurements by Bickerstaffe et al. (1972) and others gave values ranging from 9 to $26 \mathrm{~g} / \mathrm{d}$. The average rumen DM content for these sheep was $3 \mathrm{I} \mathrm{g} / \mathrm{l}$, i.e. about $25^{\circ} \mathrm{g}$ for the whole rumen. The sheep consumed maximally $45 \mathrm{~g}$ linseed oil/feed; this would give over I $50-200 \mathrm{~g}$ linseed oil $/ \mathrm{kg}$ rumen DM and under steady-state conditions most of this lipid would have to be metabolized and removed before the next feed. It is impossible to take reproducible samples of rumen contents during feeding, but when in the present series of experiments samples of rumen contents were taken as early as $0.5 \mathrm{~h}$ after feeding, the concentration of lipids in the rumen increased very little with respect to the value before feeding, and on many occasions actually decreased and increased steadily $3-8 \mathrm{~h}$ after feeding. The linseed oil was intimately mixed with the food and it is unlikely that both the food and the linseed oil would completely by-pass the rumen. It is more likely that the ingested food forms a compartment that is initially 
inaccessible to micro-organisms, that the added lipid is released slowly into the bulk of the rumen contents, presumably by hydrolysis, and that a large proportion flows out of the rumen without being metabolized.

A large proportion of the radioactivity was found in the complex lipid fraction that also contained pigments. This would suggest that the lipids synthesized were largely structural or of the 'protective-layer' type. If we assume that there are $3 \circ \mathrm{g}$ microbial DM formed/mol VFA (Van Nevel, Henderickx \& Demeyer, 1972), the microbial DM synthesized and leaving the rumen in these experiments would be about $80 \mathrm{~g} / \mathrm{d}$. It is unlikely that all the micro-organisms synthesize large amounts of lipids, therefore the estimated daily lipid synthesis $(8 \mathrm{~g})$ would give a lipid content of 10-20\% of microbial DM. This is much larger than the accepted value of $3-5 \%$.

These results show that even with apparently matched animals receiving identical treatment there could be considerable variation in lipid metabolism in the rumen. In this experiment the microbial population of one animal behaved differently from those of the other three sheep in that the micro-organisms of that animal synthesized more fatty acid. An examination of other variables showed that this particular animal had a somewhat smaller rumen volume, slower dilution rate and in general higher concentrations of substances in the rumen. The higher concentrations of substances were probably a consequence of a low dilution rate, but it is unusual for a low dilution rate to be associated with a small rumen. It is impossible to say how the changes in the above variables could produce changes in microbial lipid metabolism.

The authors thank Mrs C. Faulds for assistance in the analytical work.

\section{REFERENCES}

Alexander, R. H. \& McGowan, M. (rg66). F. Br. Grassld Soc. 2r, 140.

Bickerstaffe, R., Noakes, D. E. \& Annison, E. F. (1972). Biochem. F. 130, 607.

Blaxter, K. L. (1967). The Energy Metabolism of Ruminants, and ed., p. 21 I. London: Hutchinson Scientific and Technical.

Christie, W. W. (1974). Scan (Pye-Unicam Ltd) no. 4, p. 2 I.

Christie, W. W. \& Hunter, M. L. (1973). Biochim. biophys. Acta 326, 282.

Conway, E. J. ( 1962). Microdiffusion Analysis and Volumetric Error, p. 234. London: Lockwood.

Czerkawski, J. W. (1966). Br. F. Nutr. 20,833.

Czerkawski, J. W. (1973). Y. agric. Sci., Camb. 81, 517.

Czerkawski, J. W. (1974). F. Sci. Fd Agric. 25, 45.

Folch, J., Lees, M. \& Sloane Stanley, G. H. (1957). F. biol. Chem. 226, 497.

Hungate, R. E., Reichl, J. \& Prins, R. (I97I). Appl. Microbiol. 22, I 104.

Hydén, S. (I961). K. LantbrHögsk. Annlr 27, 5 I.

Meynell, G. C. \& Meynell, E. (1965). Theory and Practice in Experimental Bacteriology, p. 12. London: Cambridge University Press.

Ørskov, E. R., Fraser, C. \& McDonald, I. (1971). Br. F. Nutr. 25, 243.

Pye-Unicam Ltd (1968). Technical Sheet No. 24. Cambridge: Pye-Unicam Ltd.

Sutton, J. D., Storry, J. E. \& Nicholson, J. W. G. (I970). J. Dairy Res. 37, 97.

Van Nevel, C., Henderickx, H. \& Demeyer, D. (1972). Proc. 2nd Wld Congr. Animal Feeding, Madrid, vol. $5, \mathrm{p}, 27$. 